\title{
ELECTRIC OPHTHALMOSCOPES
}

To the Editor of The British Journal of Ophthalmology

SIR,-Last year, after having used an ordinary electric ophthalmoscope for some time, I found that if the light was sufficiently powerful to see the disc in an ordinary room, there was a haze round the slot in the mirror, and also from the transverse beam.

I tried various forms of -mirrors-glass, steel, and silver--but could not obviate this haze, and back light from the slot. I then tried building a small hood round the slot, but found this interfered somewhat with the vision.

As a last resort I decided to try having a glass prism slotted. This I entrusted to Messrs. George Spiller, Ltd., who took a careful interest in the work, and produced a small, silvered prism, with a slot for vision. 'With this they have now made for me an ophthalmoscope, from which there is no back light, or haze, so that the light can now be much stronger, and a good view of the disc obtained in full daylight.

Yours truly,

Bushey, Herts.

D. Hardcastle.

May 8th, 1923.

\section{NOTES}

WE regret to announce the death of CHARLES

Deaths

Killick, of Bradford, at the age of 48 years.

He appears to have infected his finger while examining an ophthalmic patient, and died from septicaemia ten days' later, on April $2 \tau$ last. $\mathrm{He}$ was buried in Undercliffe Cemetery, Bradford. He leaves a widow and two sons and two daughters (still children) to mourn his premature decease. Killick was born at Rawdon, Yorks, the son of Henry Fison Killick, a well-known lawyer practising his profession in Bradford, now retired and living at Bournemouth. Charles Killick was educated at Rossal Preparatory School, Montreux, and Bradford Grammar School. In due course he went to Cambridge (Trinity College), and after taking his arts degree with honours in the natural science tripos, he gained a university scholarship at St. Mary's Hospital, London. From the first he showed an inclination towards eye work. He went to Maidstone as house surgeon to the Kent County Ophthalmic Hospital, remained in that town as an ophthalmic surgeon, and 